\title{
Tubulostromal Adenoma
}

National Cancer Institute

\section{Source}

National Cancer Institute. Tubulostromal Adenoma. NCI Thesaurus. Code C79953.

A benign ovarian epithelial tumor. It has been described in mice and rats and is rare in

other animal species. Morphologically it is characterized by the presence of tubular structures and interstitial stroma. 